\title{
Assessment of symphysio-fundal height (SFH) and its implication during antenatal period
}

\author{
Kishor P. Chauhan* \\ Department of Obstetrics and Gynaecology, Dhiraj Hospital, SBKS Medical Institute and Research Centre, Pipariya, \\ Ta- Waghodia, Vadodara-391760, Gujarat, India \\ Received: 17 June 2013 \\ Accepted: 29 June 2013 \\ *Correspondence: \\ Dr. Kishor P. Chauhan \\ E-mail: kishorchauhan52@yahoo.com \\ (C) 2013 Chauhan KP. This is an open-access article distributed under the terms of the Creative Commons Attribution \\ Non-Commercial License, which permits unrestricted non-commercial use, distribution, and reproduction in any \\ medium, provided the original work is properly cited.
}

\begin{abstract}
Background: The aim of antenatal care is to ensure that every pregnancy is given the maximum chance to culminate in the delivery of a healthy baby without impairing the health of the mother. Symphysio fundal height (SFH) is an essential part of examination of pregnant women. In this study we discuss various formulas and USG for determining gestational age and applying them on our population.

Methods: This is a prospective observational study done at the Department of Obstetrics and Gynecology, Dhiraj General Hospital from January 2012 to January 2013. Total of 1056 eligible women were enrolled for the study.

Results: According to our study, gestational age calculated by Mac Donald's formula and USG based on Tokyo \& Osaka charts were more near to gestational age calculated by LMP. The gestational age calculated by USG based on European charts coincided with gestational age calculated by LMP up to 32 weeks, but after 32 weeks it did not correlate with LMP.

Conclusion: In our population most of deliveries occur at home and primary centers, where facility for USG is not available. Hence application of Mac Donald's formula for calculating gestational age from SFH is a better option for detection of abnormal growth.
\end{abstract}

Keywords: Symphysio fundal height, Gestational age, Fetal growth restriction

\section{INTRODUCTION}

The aim of antenatal care is to ensure that every pregnancy is given the maximum chance to culminate in the delivery of a healthy baby without impairing the health of the mother. Fundal height assessment is an inexpensive method for screening for fetal growth restriction. It has had mixed results in the literature, which is likely to be because of a wide variety of methods used. A standardised protocol of measurement by tape and plotting on customised charts is presented, which in routine practice has shown to be able to significantly increase detection rates, while reducing unnecessary referral for further investigation. ${ }^{1}$ Symphysio fundal height (SFH) is an essential part of examination of pregnant women. With advent of USG, there is a tendency not to take this important parameter into consideration by physicians in general, even though all recent evidences have proven the value of SFH in judging the period of gestation with some very few short comings. Clinicians are biased in their fundal height measurements by knowledge of gestational age and use of a marked measuring tape. This tendency increases with higher patient BMI and with less provider experience. ${ }^{2}$ Where ultrasound is not available, fundal height measurement can be used as a proxy for estimating the gestational age of the pregnancy, or the weight of the fetus. $^{3}$ Relative growth of the SF height seems to be independent of fetal sex, maternal obesity and parity. ${ }^{4}$ There is the issue of clinicians being biased in the measurement of the SFH after knowing the gestational age (Jelks 2007). Despite this, SFH measurement continues to be used in many countries on a large scale simply because of its low cost, ease of use, and need for 
very little training. ${ }^{5}$ Careful monitoring of fetal growth and wellbeing, combined with appropriate timing and mode of delivery, can best ensure a favorable outcome. ${ }^{6}$

In this study we discuss various formulas and USG for determining gestational age and applying them on our population.

\section{Aims of the Study}

1. To evaluate the value of SFH in normal antenatal care.

2. To evaluate the value of Mac Donald's formula \& Linear formula in judging the period of gestation.

3. To evaluate the value of USG in judging the period of gestation in relation to $\mathrm{SFH}$.

\section{METHODS}

This is a prospective observational study done at the Department of Obstetrics and Gynecology, Dhiraj General Hospital from January 2012 to January 2013.

Total of 1056 eligible women were enrolled for the study.

\section{Inclusion Criteria}

1. All antenatal patients who knew her LMP.

2. 24 to 40 weeks without any complication.

3. Irrespective of age and parity.

\section{Exclusion Criteria}

1. LMP not known.

2. Pregnancy with HTN, DM, Infection and other medical disorders.

3. Polyhydramnios, oligohydramnios, multiple pregnancy, known IUGR and transverse lie.

\section{Study Design}

All the eligible patients were explained about the procedure and their written informed consent was taken.

Patients who came to the OPD, detailed history was taken including LMP, Parity, TT immunization and General examination were done.

On abdominal examination symphysio-fundal height was taken in all patients by measuring tape in centimeters from upper border of symphysis pubis to fundus after centralizing the uterus \& evacuating the bladder with legs straight. Sonography was done in all patients.

\section{Mac Donald's formula:}

Gestational age in weeks $=\mathrm{SFH}$ in $\mathrm{cms} \times 8 / 7$
Gestational age in weeks $=\mathrm{SFH}$ in $\mathrm{cms}$

All the data were collected with the above mentioned methods and entered in to epi info version 3.5.3 and $\mathrm{Z}$ test was applied.

\section{RESULTS}

The table 1 shows patients we studied from 24 weeks to 40 weeks and calculation of gestational age by various formulas and comparing them with GA by LMP in our populations. The gestational age calculated by MacDonald's formula is consistent throughout with the LMP of the patient closely followed by the gestational age calculated by USG by Tokyo and Osaka charts.

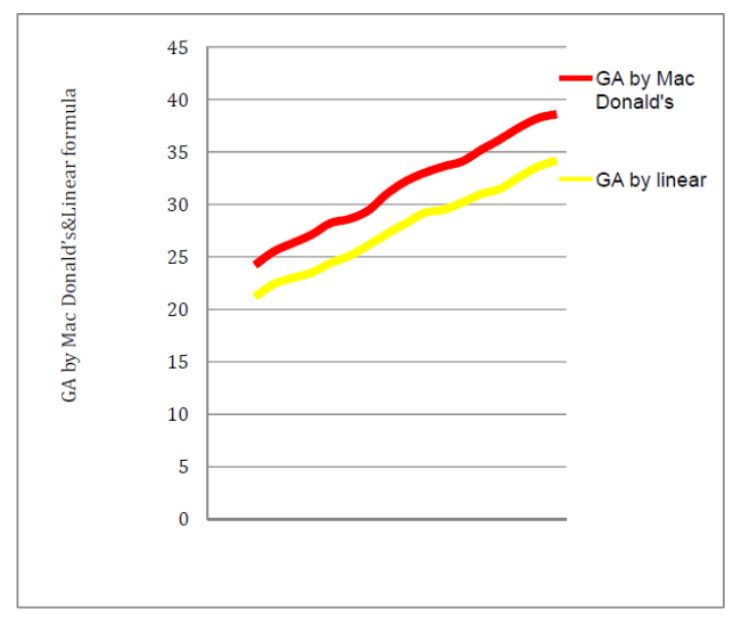

Figure 1: GA by Mac Donald's \& Linear formulas.

When comparing gestational age by LMP with gestational age by Mac Donald's formula, $\mathrm{Z}$ value is 14.75 and $\mathrm{P}$ value is less than 0.001 which is highly significant

When comparing gestational age by LMP with gestational age by linear formula, $\mathrm{Z}$ value is 1.93 and $\mathrm{P}$ value is more than 0.05 which is not significant.

- When comparing gestational age by LMP with gestational age by USG based on Tokyo \& Osaka charts, $\mathrm{Z}$ value is 13.45 and $\mathrm{P}$ value is less than 0.001 which is highly significant.

- When comparing gestational age by LMP with gestational age by USG based on European charts, $\mathrm{Z}$ value is 8.25 and $\mathrm{P}$ value is less than 0.001 up to 32 weeks which is highly significant whereas after 32 weeks $\mathrm{Z}$ value is 2.63 and $\mathrm{P}$ value is less than 0.05 which is significant.

Gestational age by MacDonald's formula is thus consistently correlating with the actual LMP of the patient and proves to be a superior method than all others in calculating the symphysio fundal height of the patient.

\section{Linear formula:}


Table 1: The gestational age derived by SFH using Mac Donald's formula, Linear formula and USG (Using Tokyo, Osaka, and European charts).

\begin{tabular}{|c|c|c|c|c|c|c|}
\hline $\begin{array}{l}\text { Gestational } \\
\text { age by LMP } \\
\text { (weeks ) }\end{array}$ & $\begin{array}{l}\text { No. of } \\
\text { patients }\end{array}$ & $\begin{array}{l}\text { SFH } \\
\text { (cms) }\end{array}$ & $\begin{array}{l}\text { Gestational age } \\
\text { by Mac Donald's } \\
\text { formula } \\
\text { (weeks/days) }\end{array}$ & $\begin{array}{l}\text { Gestational age } \\
\text { by linear } \\
\text { formula } \\
\text { (weeks/days ) }\end{array}$ & $\begin{array}{l}\text { Gestational age } \\
\text { by USG based } \\
\text { on Tokyo \& } \\
\text { Osaka chart } \\
\text { (weeks/days) }\end{array}$ & $\begin{array}{l}\text { Gestational } \\
\text { age by USG } \\
\text { based on } \\
\text { European } \\
\text { chart } \\
\text { (weeks/days) }\end{array}$ \\
\hline 24 & 61 & 21.2 & $24 / 2$ & $21 / 2$ & $23 / 5$ & $24 / 1$ \\
\hline 25 & 60 & 22.4 & $25 / 5$ & $22 / 4$ & $25 / 4$ & $25 / 3$ \\
\hline 26 & 74 & 23 & $26 / 3$ & 23 & $25 / 6$ & $26 / 2$ \\
\hline 27 & 69 & 23.5 & $27 / 1$ & $23 / 5$ & $27 / 3$ & $27 / 1$ \\
\hline 28 & 64 & 24.4 & $28 / 2$ & $24 / 4$ & $28 / 1$ & $27 / 6$ \\
\hline 29 & 73 & 25.1 & $28 / 6$ & $25 / 1$ & $28 / 5$ & $29 / 2$ \\
\hline 30 & 68 & 25.8 & $29 / 4$ & $26 / 1$ & $29 / 4$ & $29 / 6$ \\
\hline 31 & 77 & 26.9 & 31 & $27 / 2$ & $30 / 6$ & $30 / 5$ \\
\hline 32 & 76 & 28.2 & $32 / 2$ & $28 / 2$ & $30 / 5$ & $31 / 6$ \\
\hline 33 & 74 & 28.9 & 33 & $29 / 2$ & $31 / 6$ & $33 / 1$ \\
\hline 34 & 78 & 29.5 & $33 / 6$ & $29 / 5$ & $33 / 4$ & $34 / 3$ \\
\hline 35 & 54 & 29.8 & $34 / 1$ & $30 / 2$ & $34 / 3$ & $35 / 1$ \\
\hline 36 & 49 & 30.7 & $35 / 2$ & 31 & $35 / 3$ & $35 / 6$ \\
\hline 37 & 51 & 31.5 & $36 / 2$ & $31 / 5$ & $35 / 6$ & $36 / 5$ \\
\hline 38 & 52 & 32.6 & $37 / 3$ & $32 / 6$ & $37 / 1$ & $37 / 6$ \\
\hline 39 & 35 & 33.6 & $38 / 2$ & $33 / 6$ & $38 / 3$ & $39 / 1$ \\
\hline 40 & 41 & 33.9 & $38 / 6$ & $34 / 2$ & $38 / 4$ & $39 / 5$ \\
\hline
\end{tabular}

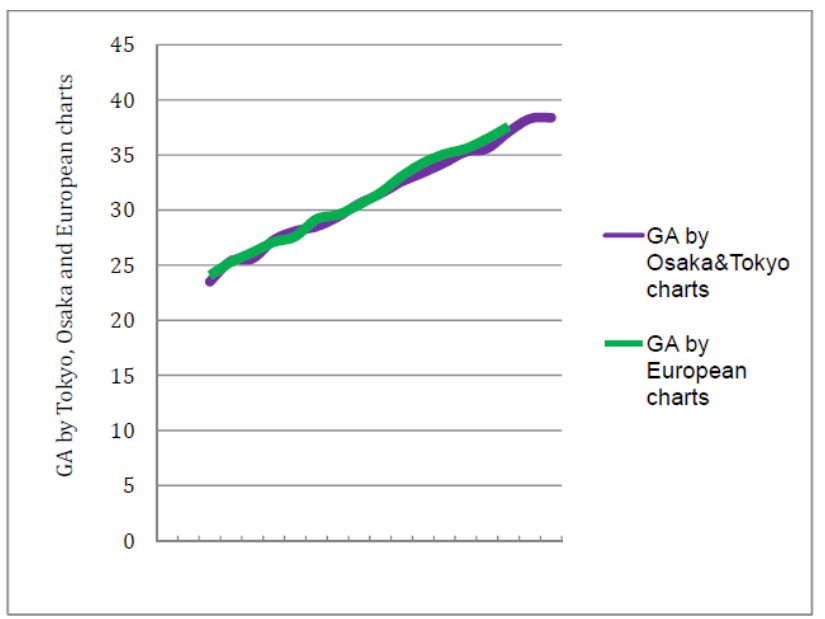

Figure 2: GA by Tokyo, Osaka and European charts.

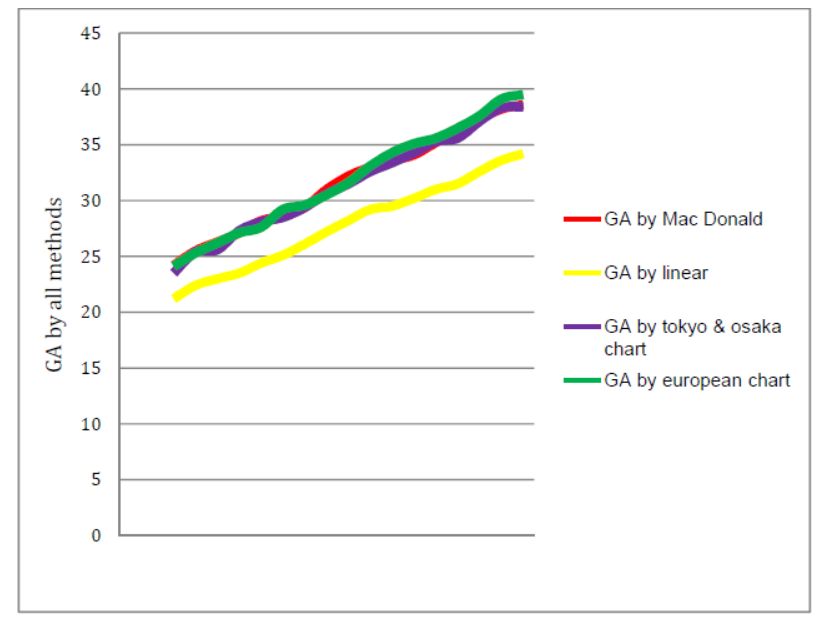

Figure 3: GA by all methods. 


\section{DISCUSSION}

So according to our study, gestational age calculated by Mac Donald's formula and USG based on Tokyo \& Osaka charts were more near to gestational age calculated by LMP.

The gestational age calculated by USG based on European charts coincided with gestational age calculated by LMP up to 32 weeks, but after 32 weeks it did not correlate with LMP.

Current national clinical guideline recommends that SFH should be measured and recorded at each antenatal appointment from 24 weeks gestation (NICE 2008).

Measuring the fundal height can be an indicator of proper fetal growth. Women receiving nutrition supplements showed significant increase in SFH as well as AC, and their babies' birth weight was higher. It is imperative to identify markers at an earlier period so as to establish the risks and extent of required interventions to improve the overall conditions during pregnancy. It is clear that the end of the second trimester is an important landmark for completion of maximum changes in fetal development. SFH can be used to study their association with birth weight at the end of the second trimester.

Standardised protocol for serial SFH measurement using a tape measure and plotting the measurements on customised growth charts has proved to be more effective in the antenatal detection of both small and large babies for gestational age, as well as in the reduction of unnecessary obstetric referrals.

\section{CONCLUSION}

According to our study, application of Mac Donald's formula and USG based on Tokyo \& Osaka charts for calculation of gestational age in our population is better than linear formula and USG based on European charts.USG based on European charts correlate with our population up to 32 weeks but after that growth of fetus is less in our population as compared to European population. In our population most of deliveries occur at home and primary centers, where facility for USG is not available. Hence application of Mac Donald's formula for calculating gestational age from $\mathrm{SFH}$ is a better option for detection of abnormal growth.

\section{REFERENCES}

1. Morse K, Williams A, Gardosi J. Fetal growth screening by fundal height measurement. Best Pract Res Clin Obstet Gynaecol. 2009 Dec;23(6):809-18.

2. Jelks A, Cifuentes R, Ross MG. Clinician bias in fundal height measurement. Obstet Gynecol. 2007 Oct;110(4):892-9.

3. Gardosi J, Francis A. Controlled trial of fundal height measurement plotted on customized antenatal growth charts. BJOG. 1999;106(4):309-17.

4. Bergman E, Axelsson O, Kieler H, Sonesson C, Petzold M. Relative growth estimated from selfadministered symphysis fundal measurements. Acta Obstet Gynecol Scand. 2011 Feb;90(2):179-85.

5. Robert Peter J, Ho JJ, Valliapan J, Sivasangari S. Symphysial fundal height (SFH) measurement in pregnancy for detecting abnormal fetal growth. Cochrane Database Syst Rev. 2012 Jul 11;7:CD008136.

6. Resnik R. Intrauterine growth restriction. Obstet Gynecol. 2002;99:490-6.

DOI: $10.5455 / 2320-1770 . i j \operatorname{cog} 20130920$

Cite this article as: Chauhan KP. Assessment of symphysio-fundal height (SFH) and its implication during antenatal period. Int $\mathrm{J}$ Reprod Contracept Obstet Gynecol 2013;2:363-6. 